$\frac{12}{5} 30-95950$

UCRL-ID-119315

\title{
A Preliminary Study of Extraction Solvents for CW-Agents and Their Decomposition Products [3:1 (Methylene Chloride:Isopropanol) vs. Methylene Chloride]
}

\author{
Armando Alcaraz \\ Raymond L. Ward \\ Suzanne S. Hulsey \\ Brian D. Andresen
}

September 15, 1994

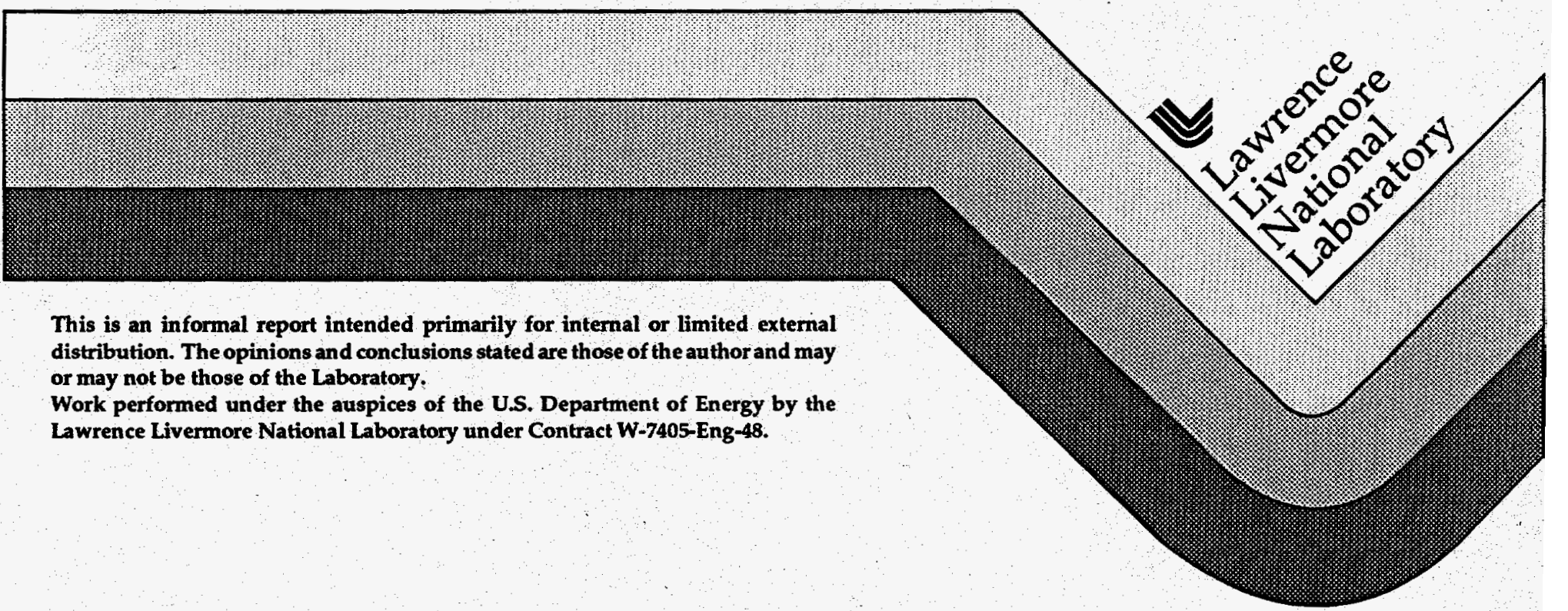




\section{DISCLAIMER}

This document was prepared as an account of work sponsored by an agency of the United States Government. Neither the United States Government nor the University of California nor any of their employees, makes any warranty, express or implied, or assumes any legal liability or responsibility for the accuracy, completeness, or usefulness of any information, apparatus, product, or process disclosed, or represents that its use would not infringe privately owned rights. Reference herein to any specific commercial products, process, or service by trade name, trademark, manufacturer, or otherwise, does not necessarily constitute or imply its endorsement, recommendation, or favoring by the United States Government or the University of California. The viewsand opinions of authors expressed herein do not necessarily state or reflect those of the United States Government or the University of California, and shall not be used for advertising or product endorsement purposes.

This report has been reproduced directly from the best available copy.

Available to DOE and DOE contractors from the Office of Scientific and Technical Information

P.O. Box 62, Oak Ridge, TN 37831

Prices available from (615) 576-8401, FTS 626-8401

Available to the public from the

National Technical Information Service

US. Department of Commerce

5285 Port Royal Rd,

Springfield, VA 22161 


\section{DISCLAIMER}

Portions of this document may be illegible in electronic image products. Images are produced from the best available original document. 


\section{BACKGROUND:}

The major focus of this study was to explore the possibility of using different extraction solvents (or solvent combinations) to isolate $\mathrm{CW}$ agents and their degradation products from environmental and industrial samples. Lawrence Livermore National Laboratory (LLNL) has developed sample work-up procedures for the preparation of $\mathrm{CW}$ samples for Gas Chromatography-Mass Spectrometry (GC-MS) analysis [1,2] . The LLNL sample work-up procedures allowed for a wide range of substrates (soils, water, swipes, rubber gaskets, etc.). The general approach for extracting, e.g. water samples, required the use of a 3:1 [methylene chloride:isopropanol, (3:1,volume: volume)] extraction solvent. In the case of soils or swipe samples a 1:3 [isopropanol:methylene chloride, (1:3, volume:volume)] was utilized as the extraction solvent. It should be noted that these LLNL sample work-up methods were developed for use in a conventional laboratory environment. The methods require ultra-sonicators, rotoevaporators, centrifuges, and large separatory funnels. Although the 3:1 solvent extraction workup methods provided excellent results in several Inter-laboratory Comparison Tests (Round Robin Exercises) ${ }^{[3,4]}$ the implementation of these methods for $\mathrm{CW}$ on-site analysis exercises was difficult (the methods require cumbersome equipment and are labor intensive).

However, due to the time, power, and size restraints set forth by the Chemical Warfare Convention (CWC) for a CW on-site inspection, LLNL developed new sample work-up methods. The approach selected by LLNL incorporated solid phase extraction (SPE) techniques ${ }^{[5]}$. This relatively new technology eliminates the need for classical sample work-up equipment, e.g. roto-evaporators, ultra-sonicators, and centrifuges. SPE also reduces the amount of solvent that needs to be evaporated for sample concentrating (also reducing the sample workup time). The new SPE methods utilized a combination of different SPE cartridges containing different polymeric phases which retained $\mathrm{CW}$-related compounds. The polymeric phases retain the target compounds and then are eluted from the SPE cartridge using specific solvents. However, during the extraction process, only two extraction solvents needed to be employed: 1) methylene chloride for moderately polar compounds and 2) water for polar compounds. The selection of extraction solvents is critical for SPE methodology, and an incorrect solvent can prevent the retention of a target compound on the SPE cartridge. 


\section{INTRODUCTION:}

The present approach for extracting organics (utilizing the LLNL SPE work-up procedures) from different substrates only utilized two extraction solvents, methylene chloride or water. We believe that other solvent systems could be investigated for their extraction efficiencies and eventually they may be incorporated into the SPE sample work-up methodology. However, during this preliminary solvent study we only focused on the 3:1 [methylene chloride:isopropanol] solvent mixture, primarily because it was used successfully in the past. In addition, there were several unanswered questions regarding the interaction of 3:1 $\left(\mathrm{CH}_{2} \mathrm{Cl}_{2}\right.$ : IPA) solvent mixture: 1) How much of the IPA remains in the water phase?, 2) During the evaporation step does all of the methylene chloride evaporate (leaving only IPA)? and 3) Is 3:1 solvent a better extraction solvent than pure methylene chloride (reconfirm past results)?

\section{EXPERIMENTAL APPROACH:}

To address the first question of how much IPA remained in the water phase, NMR spectroscopy was utilized. The proton signals from the methyl group of IPA (a doublet) and the methylene group of methylene chloride (a singlet) were measured (each area is directly proportional to the number of moles of each). Thus relative amounts of $\mathrm{CH}_{2} \mathrm{Cl}_{2}$ and IPA could be readily measured in the 3:1 solvent before and after it was used in a water extraction. Questions two and three (amount of $\mathrm{CH}_{2} \mathrm{Cl}_{2}$ remaining after the evaporation step and 3:1 solvent mix vs. pure methylene chloride) would be answered with the use of GC-MS. For example, 50 $\mathrm{ml}$ of a $5 \mathrm{ppm}$ water standard containing $\mathrm{CW}$-related compounds were extracted with 3:1 $\left(\mathrm{CH}_{2} \mathrm{Cl}_{2}: \mathrm{IPA}\right)$ and the extract concentrated for GC-MS analysis. The same procedure was repeated using only methylene chloride as the extraction solvent. The area counts from each target compound in the total ion chromatogram were measured. To determine if the majority of methylene chloride had evaporated during the concentration step, the solvent front of each extraction was examined for characteristic solvent ions (e.g. 84 and $86 \mathrm{~m} / \mathrm{z}$ for methylene chloride and 59 and $60 \mathrm{~m} / \mathrm{z}$ for IPA).

\section{Standards:}

A 3:1 $\left(\mathrm{CH}_{2} \mathrm{Cl}_{2}\right.$ : IPA) solvent mixture was prepared by combining $75 \mathrm{ml}$ of $\mathrm{CH}_{2} \mathrm{Cl}_{2}$ and $25 \mathrm{ml}$ of IPA. The 3:1 mixture was used directly for the NMR studies (no additional purification, no $\mathrm{CW}$-surrogate compounds, or drying procedures were implemented). For the GC-MS experiments the appropriate amount of a CW-surrogate standard mixture (containing four compounds) was spiked into ultra pure water to produce $100 \mathrm{ml}$ of a $5 \mathrm{ppm}$ solution. The four compounds were: 1) dimethyl methylphosphonate, 2) diethyl methylphosphonate, 3) diisopropyl methylphosphonate and 4) diethyl chlorothiophosphate. The chemicals were of the 
highest purity commercially available ( $99 \%$ or greater) and were used without further purification (purchased from Aldrich Chemical Co., including the solvents).

\section{Water Extraction:}

A $50 \mathrm{ml}, 5 \mathrm{ppm}$ water sample was placed in a cleaned $100 \mathrm{ml}$ separatory funnel. This was followed with the $20 \mathrm{ml}$ addition of the 3:1 extraction solvent (methylene chloride : isopropyl alcohol). The funnel was stoppered and shaken vigorously for 15 seconds. Upon phase separation, the solvent layer was removed and transferred to a flask. The aqueous layer was extracted one more time. The combined organic solvent extracts were evaporated to approximately $2 \mathrm{ml}$ with a stream of nitrogen at room temperature. The $2 \mathrm{ml}$ volume was rinsed with the same 3:1 solvent into a $4 \mathrm{ml}$ vial and evaporated to $200 \mathrm{ul}$ for GC-MS analysis. The identical procedure was used for the methylene chloride extraction. For the NMR experiments $50 \mathrm{ml}$ of pure water were used (without $\mathrm{CW}$-surrogate compounds).

\section{INSTRUMENTATION:}

\section{NMR Conditions:}

All samples were analyzed by proton NMR at $300 \mathrm{MHz}$ (Bruker MSL). The samples were diluted in an appropriate solvent (perdeutero dimethylsulfoxide, (DMSO- $\mathrm{d}_{6}$ ). The addition of DMSO- $\mathrm{d}_{6}$ reduces the proton intensities, which could cause problems with the dynamic range of the spectrometer. The total sample volume for the nondestructive NMR measurement was 0.3-0.5 ml. The usual conditions for quantitative proton NMR were as follows: a $90^{\circ}$ proton pulse and a sufficiently long recycle delay (10-20s) between pulses in order to allow for relaxation. The chemical shifts of the samples of isopropyl alcohol (IPA) and methylene chloride are sufficiently separated that integrations are readily performed. The integrals of the methyl group of IPA (a doublet) and the methylene group of methylene chloride (a singlet) are directly proportional to the number of moles of each; thus the relative amounts are readily measured. If absolute measurements are required, either external or internal standards are required. Usually samples tend to be contaminated with small amounts of $\mathrm{H}_{2} \mathrm{O}$. If the amount is low, a few percent, it does not cause a problem. Larger amounts of water yield signals which exceed the dynamic range of the NMR spectrometer. This excess $\mathrm{H}_{2} \mathrm{O}$ signal may prevent the quantitation of small quantities of target molecules. Drying samples with a molecular sieve or using a solvent suppression NMR pulse sequence can generally alleviate this problem.

\section{GC-MS Conditions:}

The GC/MS analysis was performed on a Hewlett-Packard model 5890 Series II gas chromatograph interfaced to a Hewlett-Packard model 5971A Mass Selective Detector (MSD, 
quadrupole mass spectrometer). The gas chromatograph was fitted with a 30 meter Supelco SPB-1, 100\% poly-(dimethylsiloxane)-bonded phase capillary column, having an i.d. of $0.25 \mathrm{~mm}$ and a 0.25 micron film thickness. Injections were done in the splitless mode ( $1.0 \mathrm{ul}$ injections) with a purge delay of $0.6 \mathrm{~min}, 7 \mathrm{psi}$ head pressure, and a purge vent of $100 \mathrm{ml} / \mathrm{min}$. Helium was used as a carrier gas and the quadrupole was scaned from 50 to 350 Daltons at a rate of 1 sec/scan. The temperature program for the GC oven was: 1 delay at $50^{\circ} \mathrm{C}$ followed by a temperature ramp of $8^{\circ} \mathrm{C} /$ minute to $310^{\circ} \mathrm{C}$. Data acquisition began at 3.0 minutes after sample injection.

The mass spectrometer was operated using electron impact ( $70 \mathrm{eV}$ and 300 micro amps), a source temperature at $170^{\circ} \mathrm{C}$, and a GC-MS interface temperature of $250^{\circ} \mathrm{C}$. A standard column mixture (Varian Associates, column test mix P/N\# 03-920273-00, Lot\# 7) was analyzed to ascertain column sensitivity and performance. Perfluorotributylamine [PFTBA, $\left(\mathrm{C}_{4} \mathrm{~F} 9\right)_{3} \mathrm{~N}$ ] was used for mass spectral calibration during the Chemstation software autotune program. The default ions used for this tuning procedure were $\mathrm{m} / \mathrm{z} 69,219$, and 502 .

\section{RESULTS:}

It was evident from the NMR data (Figure 1) that water was present in the $3: 1\left(\mathrm{CH}_{2} \mathrm{Cl}_{2}\right.$ : IPA) solvent mixture. This water contamination did not pose a major problem in determining the overall interaction of 3:1 mixture (only relative amounts were of interest). The amount of IPA which remained in the water phase after an extraction was $59 \%$. This was readily evident in Figure 2 (the NMR spectra of the water phase), as the methylene chloride (a singlet) is almost insignificant compared to the methyl group of IPA (a doublet). This significant solvent loss was a concern and a simple quantitative experiment was then designed to verify the loss. The 3:1 solvent extraction procedure was repeated and the spent extraction solvent measured with a graduated cylinder. The measured loss was $6 \mathrm{ml}$ or $60 \%$ (assuming all the loss to be IPA).

The GC-MS results indicate that the $3: 1\left(\mathrm{CH}_{2} \mathrm{Cl}_{2}\right.$ : IPA) mixture is more efficient as an extraction solvent for the four surrogate $\mathrm{CW}$ compounds in water. The amount of DMMP, DEMP, and DIMP extracted using this solvent mix was observed to be $15 \%$ higher and the level of DECITP was 30\% higher. The extracted area counts are listed in Table 1. The gas chromatography peak shapes also appears to have improved using the $3: 1\left(\mathrm{CH}_{2} \mathrm{Cl}_{2}\right.$ : IPA), contrast data in Figures 3 and 4. The improvement in chromatography peak shape may result from interaction of IPA with the poly-(dimethylsiloxane) column phase, resulting in sharper chromatographic peaks. In addition, only IPA was detected in the solvent front of the 3:1 $\left(\mathrm{CH}_{2} \mathrm{Cl}_{2}\right.$ : IPA) evaporated sample. This verifies the preferential evaporation of methylene chloride (lower boiling point solvent) during solvent evaporation and sample concentration. 
Figure 1

1H-NMR Analysis of the $\mathrm{CH}_{2} \mathrm{Cl}_{2}$ :IPA Solvent Before a Water Extraction

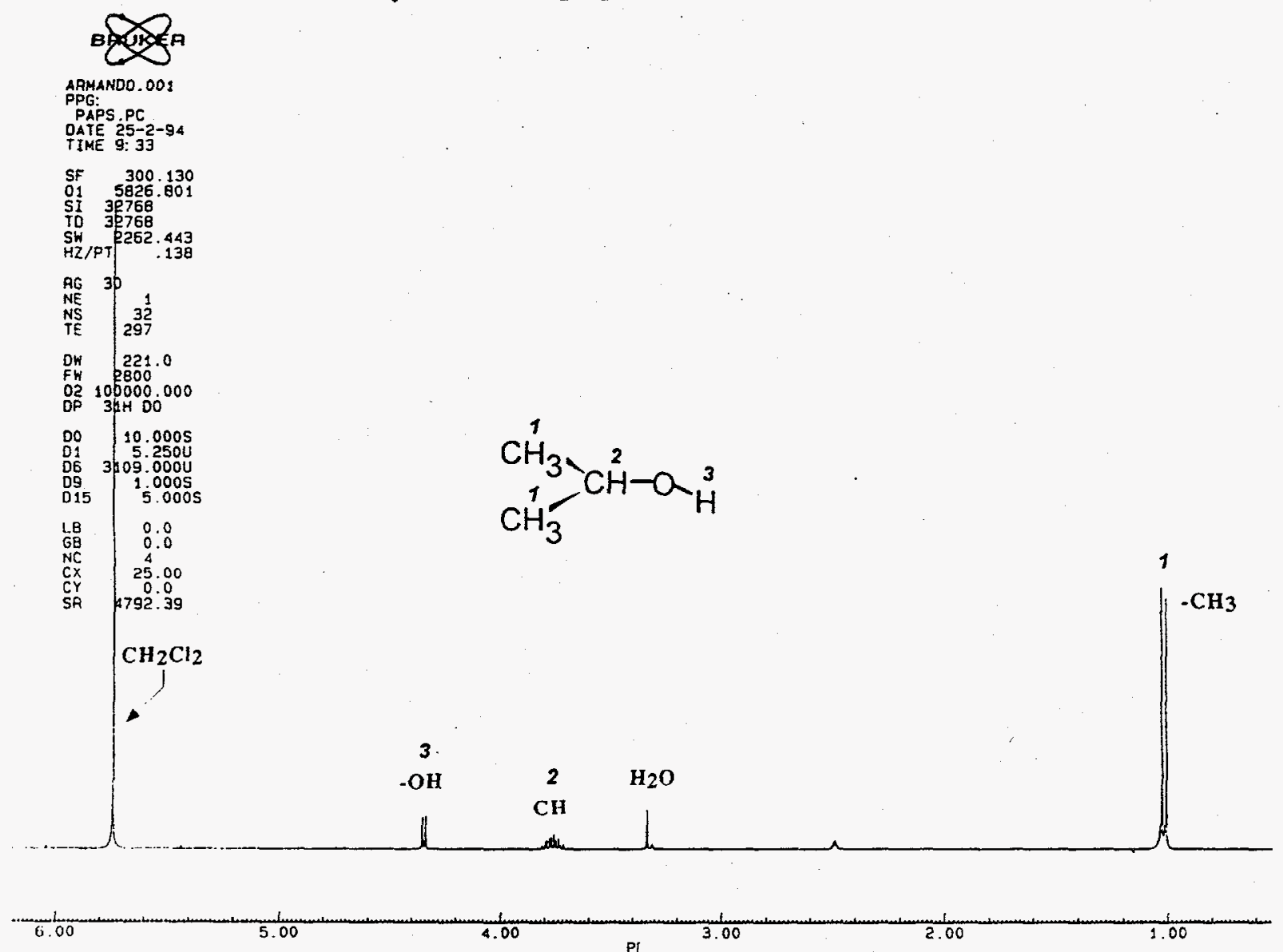

Figure 2

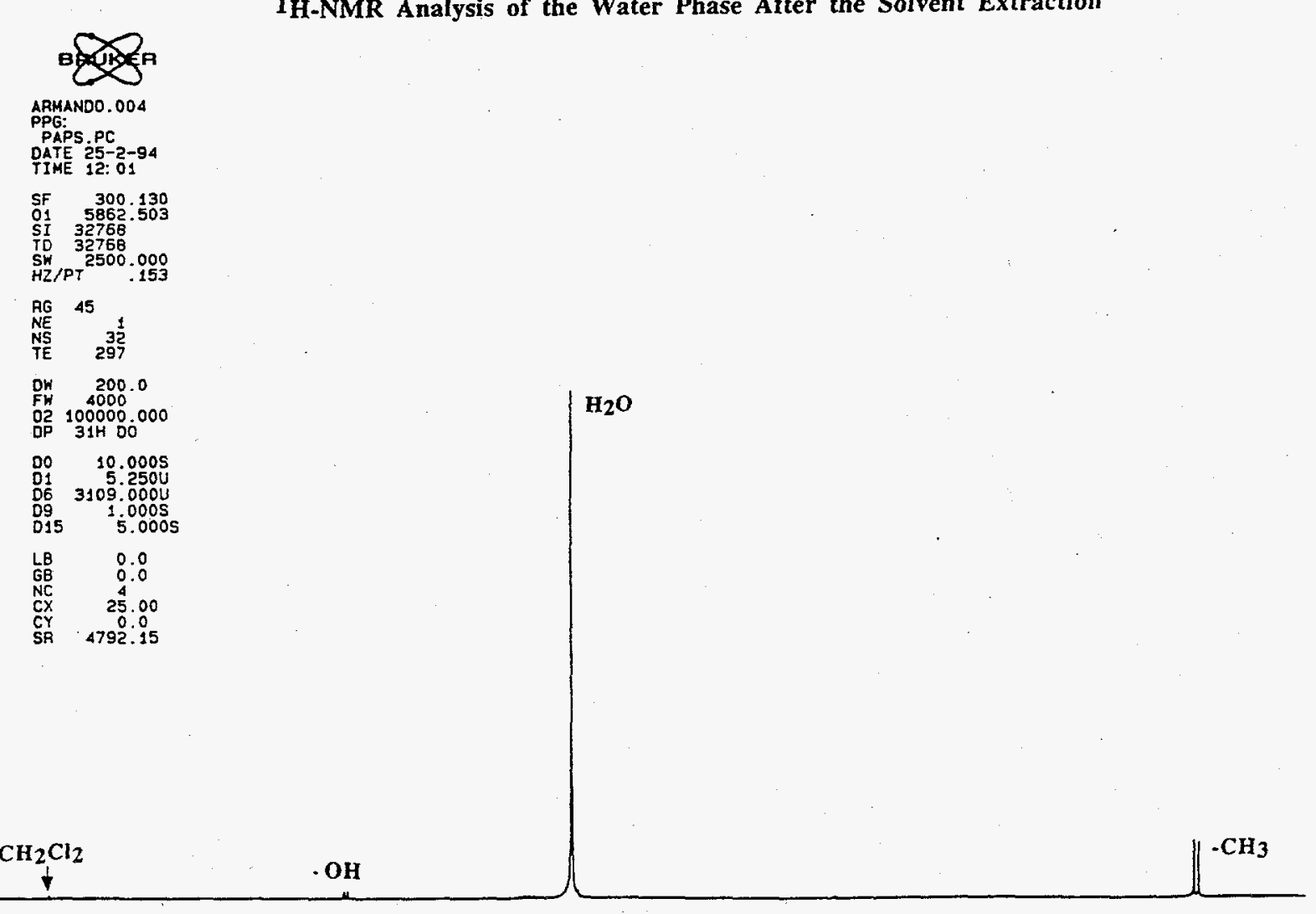


Figure 3

GC-MS Analysis of the 5 ppm Water Extract Using $\mathrm{CH}_{2} \mathrm{Cl}_{2}$

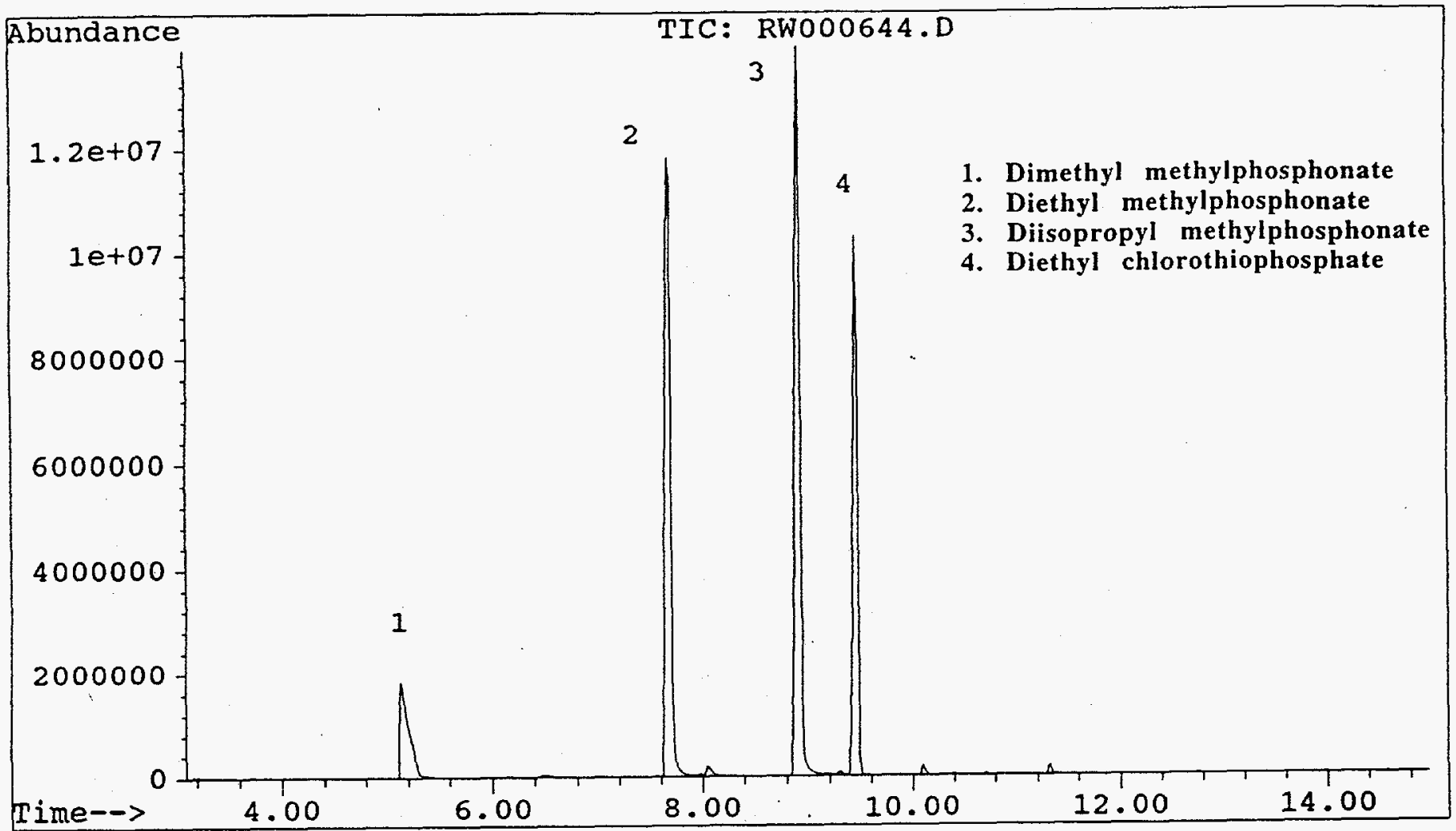

Figure 4

GC-MS Analysis of the $5 \mathrm{ppm}$ Water Extract Using $\mathrm{CH}_{2} \mathrm{Cl}_{2}$ :IPA

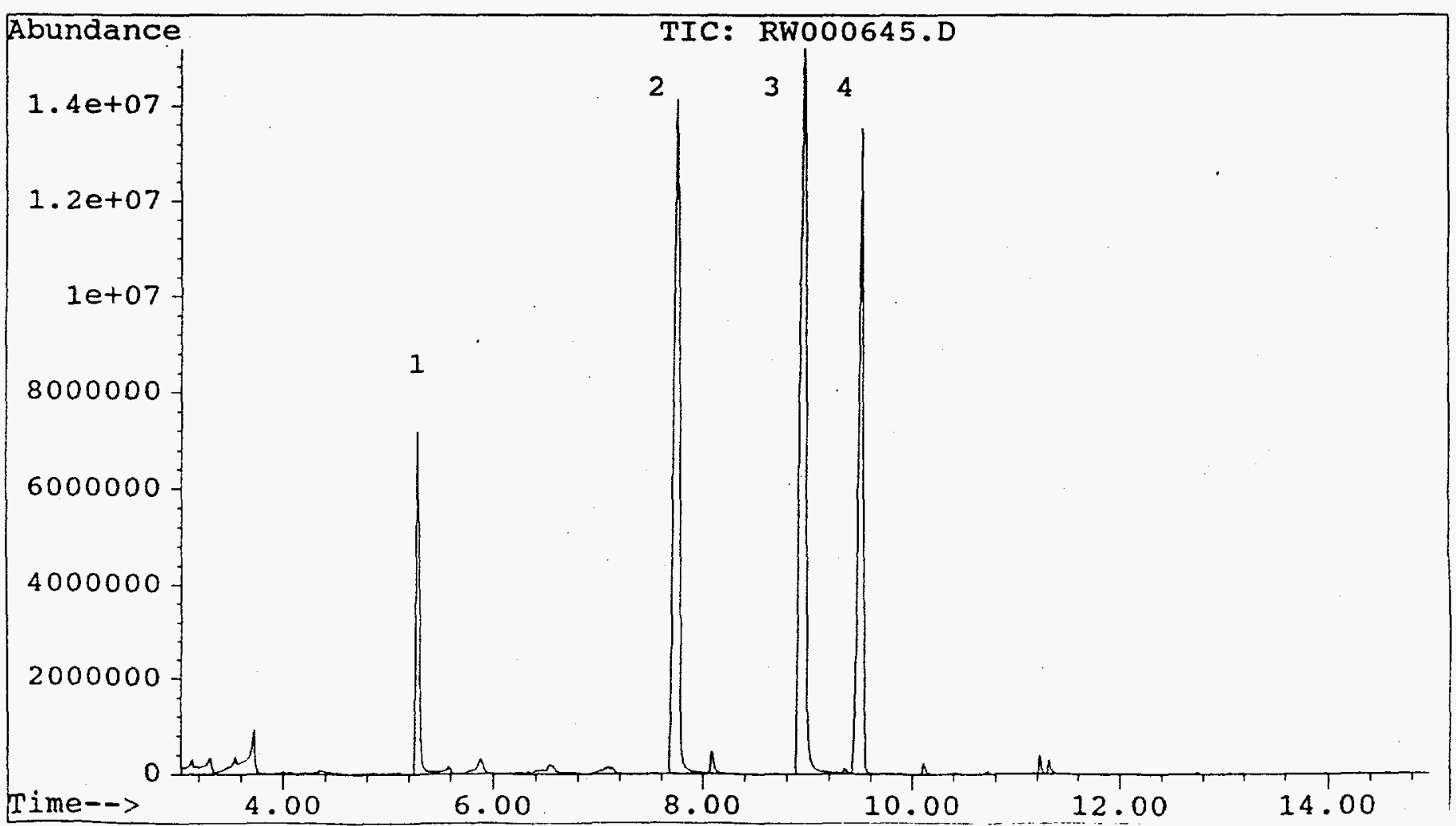


TABLE 1. Extraction study of 3:1 $\left(\mathrm{CH}_{2} \mathrm{Cl}_{2}\right.$ : IPA) vs. $\mathrm{CH}_{2} \mathrm{Cl}_{2}$

\begin{tabular}{|c|c|c|}
\hline \multirow[t]{2}{*}{ Compound } & \multicolumn{2}{|c|}{ Area Counts $\left(\times 10^{7}\right)$ for a $1 \mu l$ Injection } \\
\hline & $3: 1 \operatorname{mix}(\Delta \%)$ & $\mathrm{CH}_{2} \mathrm{Cl}_{2}$ \\
\hline DMMP & $(13 \%)$ & 11.15 \\
\hline DEMP & $51.52(16 \%)$ & 43.49 \\
\hline DIMP & $54.96(14 \%)$ & 47.13 \\
\hline DECITP & $43.23(30 \%)$ & 30.22 \\
\hline
\end{tabular}

The data listed in Table 2 indicates that the 3:1 $\left(\mathrm{CH}_{2} \mathrm{Cl}_{2}\right.$ : IPA) solvent mixture is a better solvent for extracting the selected target compounds from an aqueous sample.

\section{CONCLUSION:}

It is evident from this preliminary study that new or previously used extraction solvents should be re-investigated. A new solvent system may improve our existing on-site SPE sample work-up methods and improve the detection limits for $\mathrm{CW}$ agents and their degradation products. During this study, it was also determined that care must be taken in handling the samples prior to NMR measurements. Methylene chloride has a relatively high vapor pressure and can easily be lost by evaporation. Also, it was determined that the four target compounds used in this study were extracted on average $18 \%$ higher with $3: 1\left(\mathrm{CH}_{2} \mathrm{Cl}_{2}\right.$ : IPA) vs. $\mathrm{CH}_{2} \mathrm{Cl}_{2}$. However, additional target compounds need to be investigated using this $3: 1\left(\mathrm{CH}_{2} \mathrm{Cl}_{2}\right.$ : IPA) extraction solvent to determine which classes of compounds are better extracted by the use of a 3:1 solvent system. This preliminary study clearly reveals that a mixed solvent system can yield better extraction efficiencies for mixture of compounds in aqueous samples. 


\section{REFERENCES:}

1. B.D. Andresen and RJ. Eagle; "Procedure for the Extraction and Analysis of Environmental Samples for CW-related Compounds"; UCRL-ID-106804, 1991.

2. R. Hawley-Fedder and B.D. Andresen; Sampling and Extraction Techniques for Organic Analysis of Soil Samples"; UCRL-ID-106599, 1991.

3. International Inter-Laboratory Comparison (Round-Robin) Test For The Verification of Chemical Disarmament; F.2. Testing of Procedures on Simulated Industry Samples; Helsinki, Finland; ISBN-951-47-4957-X, 1991.

4. International Inter-Laboratory Comparison (Round-Robin) Test For The Verification of Chemical Disarmament; F.3. Testing of Procedures on Simulated Industry Samples; Finland, Helsinki; ISBN-951-47-6272-X, 1992.

5. A. Alcaraz, S.S. Hulsey, J.S. Haas, M.O. Riley, R.E. Whipple, R.R. McGuire, and B.D. Andresen; "The Development of Solid Phase Extraction Methods for CW On-site Sample Preparation In Support of the Cooperative On-site Analysis Exercise (COSAX) Project"; In Press. 